
production et la circulation de l'information

\title{
Hall Stuart : Identités et cultures 2. Politiques des différences
}

Alice Dubard

\section{(2)enEdition}

\section{Journals}

Édition électronique

URL : https://journals.openedition.org/edc/11088

DOI : $10.4000 /$ edc. 11088

ISSN : 2101-0366

Éditeur

Université de Lille

Édition imprimée

Date de publication : 1 décembre 2020

Pagination : 207-211

ISBN : ISBN : 978-2-917562-24-6

ISSN : $1270-6841$

Référence électronique

Alice Dubard, «Hall Stuart : Identités et cultures 2. Politiques des différences », Études de communication [En ligne], 55 | 2020, mis en ligne le 01 décembre 2020, consulté le 03 janvier 2023. URL : http:// journals.openedition.org/edc/11088; DOI : https://doi.org/10.4000/edc.11088

Ce document a été généré automatiquement le 3 janvier 2023.

Tous droits réservés 


\title{
Hall Stuart : Identités et cultures 2. Politiques des différences
}

\author{
Alice Dubard
}

\section{RÉFÉRENCE}

Hall S. (2019). Identités et cultures 2. Politiques des différences, Paris, Éditions Amsterdam.

1 «D'où viens-tu? ». Cette question est le tout premier énoncé de l'ouvrage. Elle est en effet posée en tête de la préface proposée par Maxime Cervulle. La réponse de Stuart Hall initiée dans la suite du livre, en fait dès l'avant-propos, semble correspondre plutôt à la question « Qui es-tu?».

2 Identités et cultures 2. Politiques des différences traite de l'influence des représentations culturelles sur celles du soi. L'ouvrage est composé de trois parties, d'un avant-propos et d'une préface signée par Maxime Cervulle et intitulée : «Faire la différence : Stuart Hall, les cultural studies et le racisme ». Cette édition que Maxime Cervulle a établie se veut être un parcours de lecture de l'œuvre de Stuart Hall présenté comme «figure majeure de la pensée critique» (p.11). La préface du tome 2 s'inscrit ainsi dans le prolongement de son récit analytique qui, sous le titre "Stuart Hall, une pensée de l'articulation », figure en préface de l'édition de 2017 du premier volume d'Identités et cultures (p. 15). Maxime Cervulle propose de donner à voir les effets des chemins théoriques empruntés par Hall sur l'étude du racisme. Par une organisation en huit points, Cervulle présente les analyses de Hall autour des questions de l'identité de manière chronologique, de son arrivée en Angleterre en tant que Caribéen à ses différentes affectations universitaires et/ou engagements institutionnels où il se découvre Noir, mais aussi de manière conceptuelle en montrant comment il relie le structuralisme des années cinquante au matérialisme culturel dans l'élaboration de sa théorie de l'articulation devenue un des piliers des cultural studies. C'est une préface un peu difficile à lire tant elle est érudite, mais qui donne envie de mieux connaître l'homme et le penseur. 
3 Stuart Hall annonce en avant-propos qu'il réfléchit, et se réfléchit, en tant que migrant. Cette caractéristique dominante de son identité, qu'il livre dans «Les moi assiégés », est importante à saisir car elle porte ses analyses.

Dans la première partie, "Ethnicité et mondialisation", Hall élabore ses théories relatives à la dimension extrinsèque de l'identité à la lumière du concept du mouvement, lequel opère à deux niveaux qui peuvent être synchrones. Le premier niveau est celui du passage des représentations au cœur des différences sociétales, c'est-à-dire ce que ce mouvement confère aux brassages et métissages culturels, et le second celui du passage de différences, c'est-à-dire qui renvoie aux mises en contact culturelles conjoncturelles révélatrices des représentations. Mais pour Hall, ces mouvements éclairés et éclairants doivent être observés, métaphoriquement, d'un lieu " posé ", qui peut désigner un territoire, une classe sociale ou encore une appartenance ethnique. Ainsi, les structures qui dessinent l'identité se distinguent dans des oppositions fluctuantes, d'où son recours à la notion de "différance » de Derrida «qui ouvre de nouvelles perspectives" (p. 99) grâce à l'orthographe du «a», laquelle introduit une signification différée à la différence mais sans exclure la nécessaire considération de la tension entre la stase et le mouvement. Hall synthétise alors : « il faut donc penser la signification non en termes de différence, mais en termes de position relationnelle au sein de la suture [...] comme si elle avait toujours un reste [...]. Ce n'est qu'en acceptant de réfléchir ainsi que nous aurons le contrôle des deux extrémités de la chaîne nécessaire à une nouvelle conceptualisation de l'identité " (p. 101). Plus loin, Hall insiste sur le travail que cela demande. Car, si « de manière paradoxale, nos identités culturelles sont devant nous» (p. 129), c'est parce qu'il faut selon lui faire l'effort de leurs productions.

5 Dans la deuxième partie, Hall «passe » la race au prisme des grands référents du régime des identifiants sociétaux communs : la biologie et la génétique, le langage, la religion, la science, et la culture assimilée à la nature, lesquelles sont confondues « à tel point que chacune fonctionne comme la métaphore exacte de l'autre» (p. 155). Hall veut montrer en quoi ces identifiants communs, que nous entendons comme des grilles de décodage général, n'ont pas permis de débarrasser les signifiants de la race des prétentions à établir des garanties sur la vérité des différences entre les Hommes. Pour Hall, la raison en est surtout politique et s'explique par le besoin intrinsèquement humain du "sommeil de la raison qui nous donne la certitude de faire ce qu'il faut» (p. 161). Ainsi, pour analyser les formations sociales où la race joue un rôle majeur par ce prisme, il divise ces tendances en deux courants dominants (" économique " et "sociologique») dans le but d'en montrer les limites, les incohérences et les dangerosités, même lorsque ces tendances se renforcent l'une et l'autre en théorie mais dans des études distinctes. Hall y adhère plus volontiers lorsqu'elles se complètent pour une explication «totale » de l'exploitation raciale, car la race est une "construction discursive ", à l'instar des analyses de John Rex à propos de l'Afrique. En justifiant leur dépassement, il entend par là même combattre le racisme, et la suite renseigne la fécondité de leurs applications inédites.

6 Dans la troisième partie, Hall interroge la "modernité » et donne à voir la manière dont elle est représentée dans les arts des diasporas noires et coloniales. En tant que «signifiant extrêmement glissant» (p.321), Hall identifie trois vagues de cette modernité, lesquelles renseignent trois moments de tensions britanniques entre ethnies: la désillusion pour la première génération de migrants de trouver en 
l'Angleterre une mère-patrie, la réappropriation de l'image du décolonisé-mais-pasencore-tout-à-fait-citoyen par celui-là même, et la lutte pour ces buts. Cette partie est riche d'exemples nominatifs précis d'artistes (photographes, sculpteurs, plasticiens) et d'auteurs qui ont contribué explicitement à faire exploser, ou pour le moins à amoindrir, le présupposé essentialiste de l'identité noire. L'hétérogénéité des contributions artistiques, tant dans leurs formes que par l'éclectisme concédé par les institutions des origines de leurs signataires à ce moment où la culture de masse se développe, favorise une réception renouvelée de la figure du Noir et de la race. Hall précise que cette évolution du regard permise par de nouvelles inscriptions générationnelles et géographiques de la diaspora et de leurs descendants allait être complexifiée par la scission, encore en prémisse mais remarquable, entre les artistes femmes et hommes dans les questions des modes de production d'œuvres au prisme de l'identité genrée. Cependant, le travail de compréhension du rôle et des effets de l'art sur l'identité n'est pas fini pour Hall et il donne ainsi des pistes complémentaires d'élucidation. Dans ce sens, il indique par exemple une rétrospective souhaitable du travail de Ronald Moody: "grand sculpteur du corps noir » (p. 329). Cette dernière partie se clôt par la mise sous projecteur de la race au cinéma avec un entretien de Stuart Hall avec Paul Gilroy et Lizbeth Goodman, enregistré le 5 mars 1993, à propos de la sortie du film de Spike Lee, Malcom X.

7 Avec ce livre, il s'agit de questionner les rapports et l'intensité de l'influence que peuvent avoir le lieu de naissance et/ou de résidence et les expériences de rencontre de l'Autre faites par soi-même ou récupérées par les différents médias sur la construction et la transformation de l'identité individuelle et collective. Deux phrases du livre résument les idées de Hall sur la nécessité, pour ce qui concerne le culturel, de mettre en relation : les endroits, les contextes politiques et économiques et les « bagages », que ces derniers soient matériels ou imaginaires. Nous les relevons, et les mentionnons ciaprès, particulièrement aussi parce qu'elles pourraient introduire la thèse que nous explorons et menons en recherche doctorale sur le patrimoine de l'Unesco : «le monde doit d'une certaine manière devenir un texte, une image, afin de pouvoir être "lu". Mais le "purement textuel" n'est jamais suffisant » (p. 354). Un rapprochement rapide entre notre sujet de recherche et la thèse de Stuart Hall pourrait s'énoncer par le slogan: performe ton héritage et enacte ta race.

8 Cet ouvrage n'est pas un pavé de 391 pages qu'on avale d'un trait, car le sujet (l'identité) est complexe, ses ramifications conceptuelles (la race, l'assimilation culturelle, l'assignation politique, l'exploitation ethnique, le mugging) le sont tout autant, les notions élaborées pour les décrire nombreuses (par exemples: " hybridation", " communautés imaginaires ", "État-client ", " assujettissement ", " eurocentrique »), et les références à d'autres chercheurs et théoriciens sont riches et hétéroclites (Foucault, Althusser, Derrida, David Scott, John Rex, C. L. R. James, Marx, Weber, Judith Butler). Certains développements sont intellectuellement abscons, en particulier toute la justification du recours à Gramsci où il faut s'accrocher pour suivre son raisonnement lorsqu'il explique que Gramsci n'est pas un théoricien "normal » dans le sens universitaire, que "ses idées sont éparpillées» (p. 243) dans des écrits parsemés, que "ses travaux sont trop concrets trop spécifiques» (p. 254) mais qu'il "peut énormément nous apporter» (p.248). En revanche, cette partie sur «La pertinence de Gramsci pour l'étude de la race et de l'ethnicité » devient plus accessible lorsque Hall met en lumière les connexions entre les conceptions clés de Gramsci (issues en partie du marxisme, telle que l'hégémonie de la classe dirigeante) et la 
théorisation du racisme dans des approches non économistes et aboutissant sur les conclusions communes de la fécondité des articulations. En outre, l'articulation est un concept qui traverse l'ouvrage et le construit, Hall le met également en exergue en parlant de la linguistique structuraliste (p. 209). L'expression est soutenue et peut rebuter, mais cet ouvrage trouvera certainement une appréciation positive auprès de ceux qui ambitionnent le mouvement de leurs pensées et de leurs représentations, et ne se laissent emprisonner par des certitudes héritées et inaltérables, qu'ils soient étudiants, enseignants, artistes, professionnels des médias ou simples curieux de la vie en société. Car, paradoxalement aux difficultés de lecture, Hall apparaît proche dans cet ouvrage qui relate son parcours intellectuel fortement réflexif, et aussi parce qu'alors que l'auteur parle «depuis » l'Angleterre, le regard qu'il propose d'adopter, sans jamais moraliser, est adaptable autant face au Commonwealth qu'aux anciennes colonies françaises. Nous concluons donc en disant que si Stuart Hall a été traversé par des limitations à être, lesquelles ont été imposées ou sous-entendues, et dans un même écho à celles d'autres intellectuels de son époque tels que Frantz Fanon dont il parle dans cet ouvrage, ce qu'il a fondé à partir d'elles, en regard de celles des autres, les "cultural studies ", est, par et pour la réflexion, libre de frontières.

\section{AUTEURS}

\section{ALICE DUBARD}

Univ. Lille, ULR 4073 - GERiiCO, F-59000 Lille, France

dubalice@yahoo.fr 